\title{
A IMPORTÂNCIA DA DISCIPLINA METODOLOGIA DA PESQUISA NO CURSO DE PEDAGOGIA: UM ESTUDO DE CASO
}

\author{
ARTIGO DE REVISÃO \\ CIECHOWICZ, Marlene Perkoski ${ }^{1}$ \\ CIECHOWICZ, Franciele Cristina ${ }^{2}$
}

CIECHOWICZ, Marlene Perkoski. CIECHOWICZ, Franciele Cristina. A importância da disciplina metodologia da pesquisa no curso de pedagogia: um estudo de caso. Revista Científica Multidisciplinar Núcleo do Conhecimento. Ano 04, Ed. 09, Vol. 04, pp. 05-25. Setembro de 2019. ISSN: 2448-0959, Link de acesso: https://www.nucleodoconhecimento.com.br/educacao/importancia-dadisciplina

\section{RESUMO}

Atualmente as universidades enfrentam um grande desafio com alunos que ingressam nos cursos de graduação com relação as produções de trabalhos científicos. Quando a pesquisa é plagiada a ampliação do conhecimento acadêmico científico fica reduzido demonstrando carência de conhecimento envolvendo a elaboração da pesquisa. $O$ exposto nesta publicação é resultado da tese de Doutorado objetivandose analisar se houve ou não a ampliação do conhecimento da disciplina de ${ }^{\left[{ }^{[3} M . C .\right.}$. Metodologia da Pesquisa Cientifica durante o transcorrer dos oito períodos em que as

1 Doutora em Ciências da Educação, pela UNISAL-Universidade de San Lorenzo (2016), Mestre, em Ciências da Educação. Especialista em Educação Infantil, Anos Iniciais, Metodologias Inovadoras Aplicadas a Educação, Gestão do Trabalho Pedagógico, Educação a Distância. Graduada em Licenciatura em Pedagogia pela UNIOESTE - Universidade Estadual do Oeste do Paraná.

2 Especialista em psicopedagogia e unidades de alimentação e Nutrição-Ênfase em gastronomia Licenciatura em Pedagogia e Nutrição. 
alunas frequentaram o curso de Pedagogia, na Modalidade ${ }^{[4]} E A D$ - Educação a Distância da [5]UNOPAR - Universidade Norte do Paraná, Polo de São Lourenço do Oeste - SC. A metodologia cientificada constituiu-se num estudo de dados analisados através de questionário semiestruturado com 8 questões abertas e fechadas aplicado a 110 acadêmicas denominando-se como pesquisa de campo, além de revisão de literatura em autores que abordavam a temática proposta. Os dados obtidos com o questionário foram tabulados com aplicação de gráficos transformados em percentuais para sistematizar os resultados e se chegar as conclusões. Conclui-se que os conhecimentos adquiridos durante o curso de graduação em pedagogia com a disciplina de $\mathrm{M}$. C foram muito significativos sendo uma ponte de conexão entre pesquisa, elaboração e conclusão dos trabalhos, demonstrando formação profissional de qualidade.

Palavras-Chave: Universidade, metodologia cientifica, conhecimento, acadêmicos.

\section{INTRODUÇÃO}

Ao produzir seus trabalhos científicos na graduação o graduando insere-se na iniciação científica, com atividades que inclui os procedimentos acadêmicos que perpassa toda a graduação, delimitando-se aqui ao curso de Pedagogia. Assim, analisando a experiência da Universidade pesquisada, procuramos interrogar as alunas do curso de Pedagogia se houve ampliação do conhecimento mediante as aulas da disciplina de Metodologia da Pesquisa Cientifica sua durante a trajetória no curso de graduação.

A metodologia científica proporciona ao acadêmico a compreensão das especificações sobre pesquisa possibilitando ao aluno ampliar seu conhecimento com coerência, coesão e parametrização necessária e exigida. Neste aspecto, ao iniciar os estudos os acadêmicos necessitam da disciplina de M.C ampliando o conhecimento nesta área, sejam capazes de produzir seus trabalhos sem plagio tendo conhecimento do caminho que devem percorrer, ou seja, conhecendo os métodos, as formas, modelo de investigação a ser empregada, as etapas que serão realizadas. 
A metodologia cientifica é o estudo dos métodos sendo importante disciplina que aborda informações, ajuda mostrar os caminhos, os instrumentos quanto aos procedimentos têm que ser adotados ao fazer um trabalho científico. Só se amplia conhecimento edificando o saber pela busca do aprendizado pela investigação tanto ao docente como o acadêmico. Esse processo de saber identificar os caminhos que se devem percorrer ao produzir conhecimento e poder colocar em prática aquilo que aprendeu é muito significativo, envolvente e cativante. $O$ docente necessita do estudo da pesquisa objetivando resultados eficazes onde o acadêmico aprenda praticar o que aprendeu e desenvolver as aptidões de raciocínio, observação, formulação e testagem de hipóteses que são pré-requisitos na pesquisa oportunizando o acadêmico adquira novos conhecimentos. (SEVERINO, 2000)

Os avanços tecnológicos estão presentes crescentemente na vida das pessoas nos possibilitando fonte de informações, e isso requer um posicionamento tanto do professor quanto do aluno ao utilizarem-se da pesquisa como fonte de informação e ampliação do conhecimento tão importante e necessário. A educação contribui significativamente desenvolvendo integralmente o sujeito, possibilita o desabrochar de seu potencial e a educação pela pesquisa representa uma oportunidade para atualização, aprimoramento e formação dos sujeitos.

Para melhor compreender o artigo exposto aqui sendo síntese da tese de Doutorado e para atingir esse objetivo, dividiu-se a investigação em cinco momentos. No primeiro instante foram apresentadas a introdução, contextualização do problema, a determinação das hipóteses, os objetivos, justificativa e a maneira como o trabalho foi estruturado, com a intenção de visualizarem o papel que a metodologia da pesquisa desempenha na ampliação do conhecimento. No Segundo momento, discutiu-se algumas questões quanto a ciência o saber apontando sua evolução e os principais representantes desta fase. No terceiro momento foram abordados reflexões acerca da metodologia e do aprendizado e seus entrelaço buscando descrever os principais tipos de conhecimentos, seus métodos e técnicas de elaboração da pesquisa. No quarto momento, interpelou-se a respeito da relevância da metodologia da pesquisa cientifica como requisito necessário e importante para produção do próprio 
conhecimento científico, as categorias do curso de licenciatura e a importância do saber docente e sua reflexão na prática. No quinto momento, constaram-se o arbouço metodológico, no último momento, discorreu-se acerca da análise e discussão dos resultados e as conclusões encontradas, averiguou-se que a disciplina de metodologia foi muito significativa sendo uma ponte de conexão entre pesquisa e criação do conhecimento na elaboração dos trabalhos científicos realizados durante os oito períodos do curso demonstrando formação profissional de qualidade.

\section{CIÊNCIA E CONHECIMENTO}

Conforme alguns pensadores a Ciência são considerados: "união do entendimento, certos ou prováveis, obtidos de forma metódica e sistematizada, verificáveis, sobre objetos de uma mesma natureza" (ANDER-EGG, apud LAKATOS \& MARC., 1991). Segundo o dicionário Priberam a palavra ciência tem origem na língua latina e significa "agrupamento de saberes fundados sobre princípios certos", entre outros significados, porém sempre relacionados ao uso e aquisição do saber. Desde os primórdios da história os indivíduos buscaram formas de melhorar o ambiente no qual vivia para facilitando sua sobrevivência garantindo a satisfação de suas necessidades básicas.

Inicialmente o homem primitivo vivia à mercê da natureza, estando vulneráveis as tempestades, raios, animais ferozes, forças sobrenaturais, tornando-se um ser frágil e com recursos esparsos. Tais motivações trouxeram um dilema: ou havia desenvolvimento ou continuaria à deriva. Assim, partindo das necessidades constatadas pelo indivíduo é que surgiu a ciência e a sua divisão nas mais distintas áreas conjuntamente ao ensino que "[...]é parte primordial da vida do homem da cultura, sociedade existindo desde quando há seres humanos sobre a terra" (LUZURIAGA, 2001, p. 2).

Muitos aspectos da ciência como se conhece atualmente surgiram na Grécia, que inicialmente pode ser classificada como Idade Antiga. Assim, nesta época teriam sido três os fatores principais que induziu a elevação do saber ou pensamento grego: a expansão da educação, a ética e Atenas tornando-se destaque intelectual da Grécia. JAEGER (2003, p. 335). Os principais representantes desta fase da ciência são: 
Sócrates, Platão, Aristóteles, Tales de Mileto, Hipócrates e Arquimedes. Estes filósofos praticaram a ciência contemplativa, ou seja, baseada na observação ambiente e são notórias as suas contribuições na medicina, astrologia, matemática, filosofia e economia.

Segundo Vicentino (2001), Sócrates viveu entre 470 a.C. e 399 a.C., período que ficou conhecido como a idade de "ouro" de Atenas. Formalizando a base da dialética socrática esteja interligada democraticamente, pois foi nesse período que houve a valorização do diálogo, da opinião, sendo que este foi o período no qual surgiram grandes oradores e iniciou-se a exaltação da retórica (CHAUÍ, 2002).

Sócrates nasceu pobre e manteve-se pobre durante o período em que viveu, pois não aceitou dinheiro de seguidores ou admiradores, sendo assim uma pessoa bastante simples. Sócrates, apesar de suas queixas às leis atenienses, foi um cidadão exemplar. Para provar isto, pode-se citar a sua participação nas campanhas bélicas atenienses, que tornaram conhecido por sua destreza e lealdade. (CHAUÍ, 2002).

Contudo, os estudos sobre as contribuições socráticas na ciência são prejudicados por terem poucas obras de sua autoria. Desta forma, as instruções e contribuições realizados por Sócrates chegaram aos dias atuais por meio das obras de Aristófanes, Xenofonte e Platão.

Sócrates não deixou obras escritas ter, mas foi responsável por inserir o pensamento crítico, desta forma, a sua contribuição para com a ciência impulsionou os indivíduos se tornarem mais críticas e responsáveis atrás de informações. Neste contexto, Teixeira et. al. (2015), aponta que o filósofo não ensinou apenas ideias, mas sim, ensinou a construí-las, ou seja, ensinou métodos para os sujeitos produzirem conhecimento.

Outro representante da ciência foi Platão nasceu em Atenas, Grécia, aproximadamente em 427 a.C. Seu nome era Arístocles. Sendo que Platão é apelido e, conforme, referências da época, tendo referência ao porte físico do filósofo (em 
grego, platôs significa precisamente "amplitude", "largueza", "extensão") (REALE \& ANTISERE, 2003).

Platão conseguiu abordar inúmeras temáticas, entre eles salienta-se: Conhecimento, Educação e Política. Platão era discípulo de Sócrates, sendo que se juntou a este melhorando sua habilidade na política. Segundo Reale \& Antisere (2003), após a condenação de Sócrates em 399 a.C., Platão se retirou de Atenas efetuando para diversas viagens. Ao voltar, fundou a Academia, estabelecimentos de aprendizagem com grande prestígio na Antiguidade Clássica. Acerca da temática conhecimento Platão tem três trabalhos tidos como principais: Teeteto, Timeu e República. O primeiro é dedicado ao estudo do que seria o saber de maneira geral; o segundo trata principalmente do Universo e o terceiro, discute a criação da cidade ideal. Diante de suas obras, principalmente a República, é notável a discussão sobre o conhecimento visível e o inteligível, sendo considerado importante no conhecimento científico. (REALE \& ANTISERE, 2003).

Aristóteles nasceu na cidade de Estagira na Grécia em 384 a.C. e foi para Atenas objetivando prosseguir e aprofundar seus estudos, desta forma estudou na Academia de Platão por, aproximadamente, vinte anos. Segundo Maciel (2009), Aristóteles foi o precursor das disciplinas modernas sendo sensato pela sistematização dos campos do conhecimento. Dessa forma, seus escritos acabam por discorrer imensa variedade de assuntos, tais como: biologia, física, lógica, ética, política e arte. Foi Aristóteles o responsável por desenvolver a política como uma ciência autônoma, ou seja, como aspecto de estudo articulada as outras, porém com seus próprios objetivos. Para Aristóteles, o indi o homem é um animal político, tendo uma tendência natural para a vivência em sociedade, sendo esta tendência a responsável pela formação das comunidades. (MACIEL, 2009).

Entre Sócrates, Aristóteles e Platão muito conhecimento foi produzido e disseminado, sendo ambos fizeram que as pessoas da época se tornassem mais crítica e capaz de analisar o meio no qual vivia e quais seriam as melhores preferencias. Tal criticidade apenas somou benefícios para as demais áreas do conhecimento, pois muitas das principais contribuições para matemática, astronomia e medicina também vieram da 
Grécia. E por tais motivações a Grécia pode ser considerada o começo da ciência. (MACIEL, 2009)

Durante a Idade Média, a humanidade presenciou difíceis episódios de intolerância e repressão. A teologia foi considerada neste aspecto ciência mais importante, sendo que as interpretações ou qualquer exercício do intelecto era limitado aos mosteiros, os quais eram, também, os responsáveis pela produção dos livros.

O renascimento e a ciência moderna tiveram mais expansão. Foram muitas as concepções formadas no decorrer da trajetória histórica da ciência acerca da elaboração do conhecimento. A ciência sofreu diversas influências filosóficas, contudo foi desde o século XVI, que se instalaram os valores filosóficos que estão muitos até hoje, atrelados ao pensamento. Assim, há o surgimento de uma mentalidade prática e utilitária que acaba por conduzir o homem à libertação da concepção medieval, na qual a religiosidade imperava sobre a ciência. Tal mentalidade considera que o sujeito seja capaz de buscar e desvendar as regras naturais, tirando proveito das mesmas. (RAMOS et. al. 2011).

Após o Renascimento, que foi um movimento atrelado tanto às artes quanto à ciência, as áreas do conhecimento tiveram mais liberdade para progredir. Em tal progressão foram feitas descobertas como: antibióticos, vacinas, meios de difusão (telefones, computadores, televisores etc.), armas nucleares, modos de viajar ao espaço, etc. Vive-se em constante processo de construção coletiva da informação, contrapondose com a Idade Média, atualmente na maior parte das informações está disponível e acessível ao grande público, tem que possuir a capacidade crítica para discernir quais aspectos serão considerados e como pode contribuir ampliando um grande acervo de saber. (RAMOS et. al., 2011).

\section{A METODOLOGIA E O CONHECIMENTO: ENTRELAÇOS}

A metodologia cientifica tem como propósito indicar o caminho certo na procura do saber, iluminando problemas para que melhor possam vê-los a assumir e a desenvolver hábitos de aprendizado e procedimentos da pesquisa que tornem 
realmente produtivos e necessário para a ampliação da aprendizagem adquirida no transcorrer do curso. A Metodologia Científica fornece um instrumental indispensável para que sejam capazes de atingir os objetivos da Academia em qualquer área do conhecimento. (LEITE, 2009)

A Linguagem Científica contida na pesquisa é uma ciência que dita algumas regras, pois, é nesse sentido que a disciplina de Metodologia Científica é eminentemente prática e deve estimular o acadêmico para que esse busque motivações para encontrar respostas às suas dúvidas. A disciplina Metodologia Científica possui significado e importância para o docente e discente quando se obtém resultado no objetivo a ser alcançado com a pesquisa. Ao ingressar na universidade o acadêmico visa conhecer e compreender que a Metodologia Científica deve ser levada a sério pois, é uma disciplina que "estuda os caminhos desse saber", se entendermos que "método" quer dizer caminho, que "logia" quer dizer estudo e "ciência", referindo-se ao próprio conhecimento. (PRODANOV, 2013).

A metodologia nos possibilita escolher o melhor caminho, tornando o trabalho/estudo mais prático e mais científico, além de resgatar nos alunos o pensar. Pensar significa passar de um nível espontâneo, primeiro e imediato a um nível reflexivo, segundo mediado. O pensamento pensa o próprio pensamento, para melhor captá-lo, distinguir a efetividade do erro. Aprende-se a pensar quando se souber fazer perguntas daquilo que é refletido. (LIBANEO 2001).

O início da investigação e ou pesquisa é muito significativo, pois, possibilita o aluno fugir do senso comum para abrir espaço para novas ideias e não só trabalho copiado como afirma Pinto (2009, p. 01) "vivemos o fenômeno do aluno-copista, que reproduz na sua pesquisa aquilo que outros disseram ou escreveram, tendo como base os valores pessoais, de crítica ou apreciação" o tão falado plágio.

Necessita-se fazer um novo conceito onde a didática e metodologia se tornem algo mais frequente e importante no decorrer da trajetória dos estudantes, facilitando então o procedimento nos trabalhos e nas pesquisas que serão desenvolvidos durante o decorrer da sua existência. $\mathrm{O}$ acadêmico precisa aprender pesquisar, pensar e fazer 
seus próprios trabalhos seguindo as regras básicas exigidas durante o decorrer do curso. (LIBÂNIO, 2002 apud PINTO, 2009)

Além de ser uma necessidade básica a disciplina de metodologia deve compor o currículo e a prática pedagógica do professor instigando o estudante a produzir seu próprio conhecimento tendo gosto e prazer em aprender produzir dentro das regras necessárias e padronizações que a metodologia cientifica oferece. "Através da reflexão e pesquisa que caracterizam a trajetória universitária do estudante". (SEVERINO, 2007, p. 17-18).

A pesquisa e a investigação são importantes, o resultado deste ato é ter informação ou noção adquirida pelo estudo é ampliar a instrução e conhecimento. O saber inclui, descrição, hipóteses, métodos, conceitos, teorias, princípios e procedimentos. (FERREIRA, 2011).

Produzir conhecimento pela pesquisa é transformar a capacidade que o indivíduo possui em informações necessárias que permitem agir com clareza, com mais segurança e determinação. Pensar nos tipos de conhecimentos é pensar, no que você sabe, ou pelo menos pensa saber. A aquisição do conhecimento se dá através da superação dos problemas buscando entender as normas acadêmicas vigentes. (PRODANOV, 2013).

Existem muitas categorias de conhecimentos dentre eles o conhecimento religioso/teológico, fundamenta-se em doutrinas que contêm proposições sagradas inspiradas em valores, inspirações, verdades exatas, conhecimento de mundo desde sua origem, finalidade, destino e origem vista como obra divina com as crenças perante estudo apresentado. (LAKATOS, 1991).

O pensamento filosófico é valorativo constitui-se de hipóteses baseando-se na experiência e não na experimentação e não verificável não confirmada e nem refutadas (Trujillo, 1974:12). Os conhecimentos que adquirimos espontaneamente no cotidiano, geralmente produzidos pela interação com todos, constituem a união de princípios empíricos intercambiáveis no convívio com os outros. 
Os conhecimentos relativos ao senso comum são diferentes do conhecimento científico, mas nem por isso menos próprios à vida. Senso comum significa aqui, certamente, não somente aquela capacidade universal que existe no sujeito, mas, de modo simultâneo, o senso que institui comunidade. O desenvolvimento deste senso comum é, por isso, de decisiva importância para a existência (GADAMER, 1998).

O conhecimento denominado popular ou vulgar corresponde ao conhecimento espontâneo que se conquista no contato que se tem com pessoas e objetos, podendo ser culturais, pelas experiências que são aceitas com passividade. "Essa variedade de saber acompanha a vida cotidianamente sem atentar-se com métodos e sem possibilitar o sujeito fazer reflexão". (BABINI, 1957 p.21).

Pode-se pensar o conhecimento científico demanda além da experimentação e observação, preocupa-se com a razão, motivo e explicação individual, possibilita conhecer novos desafios, lugares, coisas outros ambientes, outras culturas, histórias e sociedades. Possibilita formar ideias, pesquisar, analisar, refletir, contextualizar e buscar o saber.

Direcionar o trabalho do pesquisador é o propósito da pesquisa cientifica visando o aprimoramento do conhecimento novo relevante teoricamente, fidedigno e útil socialmente. Pedro Demo conceitua pesquisa cientifica como sendo "[...] por meio da pesquisa científica descobrimos a realidade" (DEMO, 1987, p. 23). Para Fred Kerlinger pesquisar "[...] é uma investigação sistemática, controlada, empírica e de apreciação de proposições hipotéticas sobre supostas relações entre fenômenos naturais gerando novos conhecimentos" (KERLINGER, 1973, p. 11).

Dentro deste contexto, temos os procedimentos que envolvem a pesquisa que são importantes pois, o aluno como pesquisador precisa saber fazer seus trabalhos conhecendo os métodos e as técnicas de produção cientifica. Na metodologia ele encontra a descrição detalhada dos métodos, técnicas e processos e deve estar predisposto a enfrentar e vencer desafios, buscando criar novos conhecimentos, procedimentos e soluções para os diversos problemas. Tais conhecimentos criados e 
alguns aperfeiçoados devem ultrapassar as barreiras da disciplina de metodologia buscando saber destacando-se na profissão.

\section{MÉTODOS E TÉCNICAS DE PESQUISA}

Os procedimentos/métodos são ações necessárias na pesquisa, através dele se obtém os métodos e a obtenção do resultado desejado. É o procedimento mais amplo de raciocínio, e as técnicas são os procedimentos mais restritos que operacionalizam o método, aplicando-se adequadamente instrumentos adequados. Nas ciências, método é denominado métodos dos processos empregados na pesquisa e na arguição da exatidão. O método científico é, pois, uma ferramenta da investigação. $O$ resultado depende de seu usuário. (SEVERINO, 2000).

O método científico é considerado o percurso onde se chega a um determinado resultado, ainda que esse caminho não tenha sido fixado de antemão de modo refletido e deliberado. (HEGENBERG, 1976). Através do método é possível descobrir a real situação dos acontecimentos e com eles conduzir o uso adequado do método da reflexão, dos fatos e dos fenômenos.

Pode-se considerar o método o percurso o caminho percorrido durante o percurso. $\mathrm{Na}$ ciência os métodos constituem os instrumentos básicos que ordenam o pensamento em sistemas, traçam de modo ordenado a maneira de proceder do cientista durante 0 trajeto de um percurso para alcançar um objetivo preocupando-se com o desempenho obtido. (TRUJILLO, 1974).

São inúmeras a variedade de investigações se que pode ter através da pesquisa, elas adotam estratégias e objeto a serem investigados, resultando na análise dos dados. Em geral, a pesquisa é qualitativa, visando o aprofundamento do dado; ou quantitativa, que procura trabalhar $\mathrm{o}$ dado imediato, mensurando, medindo $\mathrm{e}$ quantificando. Nesse sentido, destacam-se algumas modalidades de pesquisa, segundo Knechtel (2014). Pesquisa bibliográfica, de campo, documental, participante, pesquisa ação e estudo de caso. Verifica-se dois tipos gerais de pesquisa e várias modalidades podem ser executadas. 
Na pesquisa de observação é onde se aplica os sentidos físicos com o propósito obterse um resultado ou conhecimento relevante e necessário. Na ciência observar é importante, pois, dela que depende a soma dos outros processos, é na verdade um estudo real e suas leis.

A observação assume diferentes configurações, conforme Lakatos e Marconi (1988) a observação assistemática, também chamada espontânea, informal, simples, livre ou ocasional, caracteriza a observação sem observação a qualquer técnica ou instrumento, sem planejamento, sem controle e sem quesitos observacionais previamente elaborados. Observação sistemática, chamada observação estruturada, planejada ou controlada, tem como característica básica o planejamento prévio utilizando-se anotações e controle da etapa e da periodicidade, recorrendo também aos recursos técnicos, mecânicos e eletrônicos. Observação não-participante, ocorre quando o pesquisador deliberadamente se mantém na posição de observador e de espectador, evitando se envolver ou deixar-se envolver com o propósito da observação. Observação participante, ocorre quando o observador, deliberadamente, se envolve e deixa-se envolver com o tema da pesquisa, passando a fazer parte dele. Observação, em diversas situações de investigação, a observação só é concretizada individualmente, como nas pesquisas destinadas à obtenção de títulos acadêmicos, e o observador tem de submeter o estudo da pesquisa ao crivo de seus próprios conhecimentos, dada a ausência de controles externos. Observação em equipe, ocorre quando um objeto de investigação é, simultânea ou concomitantemente, observado por várias em vários tempo e lugares tendo os mesmos objetivos. Observação laboratorial, tem caráter artificial, mas é importante por isolar o objeto da pesquisa de interferências externas descobrindo mecanismos internos de funcionamento do tema devendo ser atenta, exata e completa, precisa, sucessiva e metódica.

A observação, sozinha, não é suficiente para constituir o saber e da ciência se serve. Sendo a aplicabilidade de uma noção fundamental para a validação científica de qualquer tipo de experimento, é necessário que ao concluir a observação seja cuidadosamente registrado, processo que configura a técnica científica da descrição. 
A comparação é a técnica científica aplicável sempre que houver maior quantidade de resultados com as mesmas propriedades gerais ou características particulares. Da comparação, importa abstrair as semelhanças e destacar as diferenças. Homem e mulher, por exemplo, são comparáveis na maioria de suas propriedades gerais, mas não em suas especificidades. Duas pessoas, quaisquer que sejam, são comparáveis em suas propriedades gerais referindo-se a espécie, raça, constituição biológica, constituição físico-química, estrutura, composição e desempenho, mas não são comparáveis no aspecto do significado particular que podem assumir em determinados contextos específicos, tal como a posição social que ocupam, o lugar individualmente na família entre outros.

A síntese e a Análise são dois procedimentos distintos e inseparáveis serão abordados juntos. René Descartes, na obra Discurso do método (1956), procurando traçar normas gerais e indispensáveis a qualquer trabalho científico, formulou quatro regras que são fundamentais a primeira ele aponta que é preciso conhecer a verdade e nunca o aceitas como tal, a segunda é analisar as dificuldades para melhor resolvelo, como terceiro ele destaca que é preciso sintetizar a ordem de pensamento do simples ao mais complexo, no quarto e último destaca que precisa analisar e sintetizar as revisões gerais.

A análise e a síntese experimentais constituem o cerne de toda experiência científica na pesquisa de laboratório. Liard (1979, p. 52) adverte que "conforme o objeto, a análise e ê síntese pode ser feitas por meio da separação real e, quando possível por meio da reunião das partes nos objetos materiais. São empregadas nas ciências da natureza".

\section{IMPORTÂNCIA DA METODOLOGIA DA PESQUISA PARA A CONSTRUÇÃO DO CONHECIMENTO CIENTÍFICO}

O saber acadêmico amparado pela metodologia e suas regras faz o aluno pensar, criar e entender a pesquisa. E pela pesquisa que se consegue impregnar a conexão entre técnicas e conhecimentos de forma criativa, e fazer da criatividade a base de desenvolvimento da educação universitária em sua plenitude. Uma Universidade 
destituída de emulações criativas limita-se à condição de mera repetidora daquilo que outros centros já elaboraram. (BORNHEIM, 1993).

A M. C como disciplina na universidade se faz necessária, pois, a universidade é uma instituição comprometida em ampliar o saber do sujeito, bem como da sociedade e da Humanidade. A metodologia auxilia e orienta o universitário nas normas de investigação para tomar decisões oportunas na busca do saber e na formação crítica e hábitos necessários a investigação científica. $\mathrm{O}$ uso de processos metodológicos permitirá ao estudante desenvolver o silogismo e criatividade (CERVO \& BERVIAN, 2002). A metodologia cientifica fornece aos discentes um instrumental indispensável para que sejam capazes de atingir os objetivos da academia, que são o estudo e a pesquisa em qualquer área.

A prática reflexiva é bastante difundida no campo das discussões, e incorporada a textos e documentos de forma quase integral e totalizadora (CAMPOS, DINIZ, 2004). Em meio às mudanças educacionais o processo formativo de professores reflexivos pode ser caracterizado de duas formas: pedagógica e acadêmica, que correspondem respectivamente a processos que conduzem ao exercício profissional, e a estudos específicos a nível científico sobre um tema. (MIARALET, 1991).

\section{ANÁLISE E DISCUSSÃO DOS DADOS E RESULTADOS}

O estudante quando ingressa na universidade depara-se com novas realidades e possibilidades tendo que se adequar a elas e isso requer que ele saiba seu papel diante da pesquisa. A disciplina de metodologia instrumentaliza o acadêmico abrindo caminhos com a finalidade de obter bons resultados, fazer seus trabalhos tendo desempenho pessoal ampliando o aprendizado de forma significativa, eficaz e eficiente.

O acadêmico precisa se conscientizar, que, para ampliar o conhecimento pela pesquisa ele precisa desenvolver o hábito de estudar com muita dedicação, esforço, determinação e comprometimento. Sendo assim, diariamente ler e escrever leva-nos 
a sermos consumidores do conhecimento nos dá a chance de competirmos com mais segurança naquilo que desenvolvemos. (TEIXEIRA, 2010).

As práticas em classe possibilitam a participação assídua dos acadêmicos e os estudos pessoais devem complementar a aprendizagem diante de reflexões, ações e atitudes positivas tornando o conhecimento valioso e significativo para sobrevivência. É uma prática relevante ler bons livros que embasam o estudante na produção dos seus próprios escritos.

Neste contexto, os dados foram tabulados com aplicação de gráficos, transformados em percentuais, participaram do estudo, cento e dez (110) acadêmicos do oitavo (8o) período dos cursos de Licenciatura em Pedagogia na Universidade Norte do Paraná - Polo de São Lourenço do Oeste. A universidade apresenta em seu curso a oferta de disciplinas em cursos semipresenciais. Esse critério foi determinado para verificar o grau do conhecimento dos acadêmicos acerca dos objetivos, métodos, regras e ferramentas inerentes à Metodologia Científica, antes e após seu ingresso à universidade.

$\mathrm{Na}$ primeira questão sobre a apuração da questão de gênero masculino e feminino $98 \%$ foram do sexo feminino, observa-se que ainda prevalece a escolha por mulheres na graduação em Pedagogia. O Instituto Nacional de Estudos e Pesquisas Educacionais Anísio Teixeira [6](INEP) destaca principais conquistas das mulheres no último século foi o acesso ao Ensino Superior. Dados do Censo da Educação Superior de 2016, última edição do levantamento, revelam que as mulheres representam 57,2\% dos estudantes matriculados em cursos de graduação. No Censo da Educação Superior de 2006, as mulheres representavam 56,4\% das matrículas em cursos de graduação. Para os estudiosos ainda existe diferença de gênero em postos de trabalho, a desigualdade entre gêneros ainda se dá porque há discriminação por causa dos papéis domésticos, muito mais assumidos pelas mulheres.

$\mathrm{Na}$ questão 2 observou-se nas respostas dos acadêmicos que ao ingressar na universidade o nível de conhecimento da disciplina de Metodologia Científica, 90 acadêmicos (82\%) não possuíam conhecimento, demonstrando a necessidade do 
estudante nas Series Iniciais, Ensino Médio e Superior ampliar esse conhecimento. Apurou-se que 12 (11\%) possuíam conhecimento Regular, 7 (6\%) possuíam um Bom conhecimento e somente $1(1 \%)$ tinham excelente conhecimento. As respostas a esta questão demonstraram que os acadêmicos precisam saber fazer trabalhos, artigos e projetos, onde o dever do docente neste momento é o de orientar, ensinar, trabalhar de forma clara e objetiva, tendo uma linguagem que pode mudar a conduta da estudante frente as etapas que irão surgir. A Universidade enquanto espaço desenvolvimento dos profissionais é também formadora no desenvolvimento científico e tecnológico e possibilita a produção do próprio conhecimento científico onde a pesquisa e a reflexão sejam características intelectual na vida do estudante. (FOLLMANN, 2008).

No tocante a pergunta dos atuais conhecimentos sobre os objetivos da Metodologia Cientifica, obtivemos as seguintes respostas: nenhum dos graduandos disse não ter conhecimento, 75 (68\%) apontaram ter conhecimento regular, 34 (31\%) tem bom conhecimento e 1(1\%) demonstraram excelente conhecimento. Diante das respostas fica evidenciado a contribuição e esclarecimento que a disciplina de metodologia cientifica contribuiu na trajetória da graduação.

Esta questão reconhece que a disciplina de metodologia da pesquisa oportuniza desenvolver nos acadêmicos habilidades tão importantes e necessárias como: de raciocínio, observação, formulação e testagens das hipóteses, senso crítico, solução dos problemas, de refletir, questionar, indagar, analisar, interpretar, produzir novas ideias, aprofundar métodos e técnicas, etc. (SEVERINO).

Quando questionados do atual grau do conhecimento das ferramentas, regras e métodos empregados na produção de trabalhos científicos, $88(80 \%)$ demonstraram ter de regular conhecimento, $22(20 \%)$ possui conhecimento bom e ninguém tem excelente conhecimento. As práticas pedagógicas utilizadas durante o período tiveram êxito para ampliação do conhecimento dos acadêmicos, de forma unânime $80 \%$, responderam que tem um conhecimento regular sobre as regras, ferramentas e métodos, isso demonstra que é preciso elevar esse percentual para excelente estimulando o potencial de qualquer um para atingir o conhecimento nas integrais 
etapas e chegar a conclusão do curso tendo conhecimento nesta área, pois, a disciplina de metodologia é um apoio necessário para superar os obstáculos no caminho e se constitui uma das dimensões mais importantes do fenômeno educativo (DEFOURNY e CUNHA, 2008).

Quando questionados sobre o conhecimento das principais produções científicas ao iniciar na universidade, no que tange ao Fichamento - $10(9 \%)$ responderam qual não dispunham de conhecimento, 95 (87\%) era regular seu conhecimento, 5 (4\%) já possuíam um bom conhecimento e nenhum se manifestou ter excelente conhecimento. O real objetivo do fichamento é um procedimento utilizado na elaboração de fichas de leitura onde constam informações relevantes sobre um texto lido. O leitor tem a liberdade de escrever com as próprias palavras as ideias fundamentais extraídas de um livro, um artigo etc. "Ouvir aulas [...] ler livros clássicos e célebres. Isso só tem algum valor visto quando se transforma em um documento pessoal. [...]". (SEVERINO, 2002, p. 36-37).

No Resumo - 90 (82\%) dos acadêmicos demonstraram não ter conhecimento ao ingressar no curso, 20 (18\%) tinha conhecimento regular e nenhum se manifestou ter bom ou excelente conhecimento. E assustador que $82 \%$ dos acadêmicos não tínhamos conhecimento científico na elaboração de resumo antes de cursar o ensino superior. Como educadora vejo que isso é grave, pois o resumo é uma atividade didática bastante pedida pelos professores de inúmeros cursos de graduação. João Bosco Medeiros define resumo como sendo uma apresentação sintética e seletiva das ideias da obra, ressaltando a processão e a articulação delas. (21) Já a ABTN (22) conceitua resumo como apresentação concisa dos pontos relevantes de um documento.

No tocante ao Projeto de Pesquisa 40 (37\%) não possuíam conhecimento, 55 (50\%) tinham conhecimento regular 15 (13\%) possuíam conhecimento bom e ninguém tinha um excelente conhecimento. Fica evidenciado a defasagem dos acadêmicos ao produzir seus trabalhos e isso mostra os desafios que a educação passa aonde vai desde a omissão de interesse dos alunos como dos professores ensinar desde cedo o aluno pesquisar e elaborar seus próprios trabalhos. No ensino superior o aluno 
desenvolverá conteúdos teórico-práticos, necessários à sua formação profissional e intelectual, cabendo-lhe não só a reter esses conteúdos, mas também produzir conhecimento e o projeto possibilita a investigação. (RODRIGUES, 2006).

Com relação ao Artigo - 60 (54\%) apontaram não ter conhecimento, 50 (46\%) apontaram ter conhecimento regular e nenhum tinha regular ou excelente. Apoiandose nas respostas, percebe-se a defasagem dos acadêmicos em saber as regras, normas e escrever um artigo. O artigo objetiva fazer descoberta do estudante divulgando para a comunidade acadêmica. Ao escrever um artigo científico, o pesquisador deve considerar não apenas a escrita ou a correta formatação do texto, como também o chamado Fator de Impacto. Tal fator é essencial na hora de determinar em qual periódico o artigo será publicado. Fator importante que deve ser analisado nas produções acadêmicas.

Para Perini (1996, apud BAGNO, 2007): "as habilidades de raciocínio, observação, formulação e testagem de hipóteses [...] são um pré-requisitos para a produção dos indivíduos capazes de aprender por si mesmos, criticar o que aprendem e criar conhecimento novo". PERINI (1996, apud BAGNO, 2007, p.9). É importante o aluno elaborar seus próprios conhecimentos, pois, através da pesquisa, ele adquire experiência na atuação.

Não possuíam conhecimento 58 (53\%) dos acadêmicos no Relatório de Estágio e 52 (47\%) possuíam conhecimento regular ninguém tinha bom ou excelente. As respostas denotam a real fragilidade da aprendizagem da pesquisa. Neste contexto, o estágio é uma etapa importante para a evolução da aprendizagem, porque promove oportunidades de vivenciar na prática conteúdos acadêmicos, propiciando desta forma, a aquisição de conhecimentos e atitudes relacionadas com a profissão escolhida pelo estagiário. O estágio permite conversação e compartilhamento de experiências entre os profissionais das instituições de ensino, bem como o intercâmbio de novas ideias, conceitos, planos e estratégias. A formação para a docência de qualidade deve se pautar na perspectiva investigativa, na qual a pesquisa, assumida como princípio científico e educativo, fundamenta-se na 
proposição metodológica fundamental para o rompimento das práticas de reprodução (BARREIRO e GEBRAN, 2006).

As respostas da questão anterior são iguais a próxima pergunta mudando ( $A O$ INGRESSAR NA UNIVERSIDADE) e no (AO CONCLUIR O CURSO). O grau do conhecimento adquiridos ao concluir o curso das principais produções cientificas foram assim definidos. No Fichamento, $30(27 \%)$ tem de regular conhecimento, 75 $(69 \%)$ adquiriram um bom conhecimento e $5(5 \%)$ dos acadêmicos tem excelente conhecimento. As respostas mostram que houve um avanço de aprendizado durante o período do curso. Na elaboração do fichamento o leitor deve fazer uma primeira leitura. Na segunda leitura deverá então começar a registrar as ideias chave transmitidas pelo autor. Deve certificar-se de que compreendeu muito bem aquilo que leu, pois, uma escrita clara e objetiva irá facilitar o estudo. Os estudantes têm dificuldades em resumir, encontrar as ideias centrais e detalhes do texto lido. Resumir integra a da vida dos estudos, porém, esse exercício intelectual torna-se evidente, e frequente, na universidade e profissionalmente. (A SALOMON, 2001).

Ao terminar o curso superior nenhum acadêmico manifestou conhecer Resumo e 20 (18\%) manifestaram ter de regular conhecimento, 90 (82\%) possuem bom conhecimento, ninguém respondeu que tem excelente conhecimento, isso demonstra que ainda o aluno deve ampliar seus conhecimentos diariamente. Fazer resumo através da pesquisa pode ser considerado "uma união de procedimentos sistemáticos, baseado no raciocínio lógico, objetivando encontrar soluções para problemas propostos, mediante uso dos métodos científicos" (ANDRADE, 2003 apud FONTE, 2004).

O resumo é um trabalho de extração de ideias sendo a apresentação concisa dos pontos relevantes de um documento. Para [7]NBR 6028:2003, o resumo pode ser crítico, também chamado de resenha. Pode ser indicativo, quando cita os pontos básicos do documento, mas sem apresentar dados e bem como informativo, quando específica com maiores detalhes o documento em análise. 
Os atuais conhecimentos do Projeto de Pesquisa, revelaram que todos evoluíram neste item pois, 55 (50\%) possuem conhecimento regular, 55 (50\%) tem bom conhecimento. As respostas mostram um empate $50 \%$ no conhecimento regular e bom isso mostra que houve evolução, mas, temos que melhorar muito ainda para se atingir a excelência. Todo o trabalho acadêmico precisa ser planejado antes de ser realizado. O projeto é o registro deste planejamento. Para elaborar o projeto o pesquisador precisa ter bem claro o seu objeto de pesquisa, os problemas, hipóteses, elementos teóricos e etapas que pretende percorrer. Cada item deve obedecer às normas técnicas da ABNT- Associação Brasileira de Normas Técnicas, pois elas são indispensáveis para a avaliação do projeto.

Segundo Silva (2007), constata-se que atualmente, educadores vêm encontrando grandes dificuldades em trabalhar pesquisa. Um dos motivos dessas dificuldades poderá ser a inexistência de aprimoramento na prática da pesquisa e como inseri-la no processo educacional e em sua prática pedagógica, sem gerar desinteresse por essa área. A pesquisar requer um planejamento minucioso das etapas a serem observadas, como: seleção do tema de pesquisa, definição do problema a ser investigado, processo de coleta, análise e tratamento dos dados, e apresentação dos resultados, podendo ser uma tarefa muito difícil e complexa, o que gera ainda um desinteresse maior por parte do acadêmico.

Constata-se um diferencial ao início da graduação e ao término da mesma. Considerase que o Artigo é de extrema importância na vida subsequente e somente 5 (5\%) demostraram ter conhecimento regular, 96 (87\%) consideram-se ter bom conhecimento e $9(8 \%)$ respondeu que tem excelente conhecimento. As respostas mostram que houve um entendimento no que se refere ao aprendizado para elaboração de artigo. Os artigos científicos, objeto deste estudo, podem ser divididos em artigos experimentais e artigos teóricos. Os primeiros, focos deste trabalho, objetivam expor resultados de experimentos ou levantamentos; os segundos, a proposição, defesa ou questionamento de um modelo ou teoria, sem recorrer a dados empíricos (MASSARANI; MOREIRA, 2005). A dinâmica do conhecimento no mundo depende de pesquisas e técnicas que vêm sendo estudadas e amplamente divulgadas 
para o desenvolvimento físico e intelectual da sociedade. No decorrer de novos estudos, cientistas descobrem métodos de aprimoramento primordial para a evolução humano. Mas não basta realizarem estudos e descobertas, é preciso democratizar a informação e tonar público os resultados alcançados e a publicação do artigo levam a isso.

A grade curricular de Pedagogia contempla desde o quinto período o Relatório de Estágio com isso 55 (50\%) apontaram ter evoluído no conhecimento como regular, 55 (50\%), averiguou-se que 53\% não sabiam nada ao ingressar na universidade (questão anterior) e $47 \%$ responderam regular. Considerando as respostas pode-se destacar a ampliação da aprendizagem. O relatório de estágio permite o aluno descrever suas atuações durante o período proposta a cada etapa sendo de real importância no desenvolvimento integral do estudante.

Segundo a Resolução CNE/CP 2, de 19-12-2002, que institui a duração e a carga horária dos cursos de licenciatura, de graduação plena e formação de professores da Educação Básica em nível superior, a carga horária destinada ao Estágio Curricular Supervisionado deve contemplar, no mínimo, 400 horas. A formação do professor deve ocorrer por intermédio da pesquisa e, também, da extensão, o estágio supervisionado, se torna um momento privilegiado para articular a teoria e a prática docente.

Quando indagados no tocante grau do conhecimento atual da disciplina de Metodologia Científica e das produções acadêmicas, 34 (32\%) argumentaram que ajudou a melhorar o conhecimento regularmente, 74 (67\%) bom e 2 (1\%) argumentaram que ajudou a melhorar o entendimento de excelente maneira. Considerando os desafios enfrentados ao ingressar no ensino superior no cumprir as exigências descritas pela metodologia, o aluno deverá organizar as etapas necessárias à produção de seu texto, o professor deve ser o articulador desse processo motivando, cobrando, orientando o aluno para que ele desperte o habito de ler, escreve, pesquisar e publicar inovações, pois, o objetivo da docência é melhorar os resultados da aprendizagem instigando o acadêmico esforçar-se didaticamente 
para adequar-se a organização dos cursos e os métodos de ensino utilizados aos diferentes modos e estilos de aprendizagem. (ZABALZA, 2004).

Como deveriam ser conduzidas as aulas da disciplina de Metodologia Científica para melhorar o nível de pesquisa das produções acadêmicas percebe-se nas respostas que ninguém discorreu em ficar como está, 8 (7\%) descreveram que deveria haver mais carga horária e 7 (6\%) escreveram que deveria ter mais uso e costume para ter mais conhecimento da disciplina e quase unanimidade 95 (87\%) sugeriram que deveria ser mais carga horária, teoria, prática e cursos para ampliar o grau do conhecimento sobre as regras de pesquisa das produções acadêmicas.

Mais carga horária, mais teoria aliada a prática são apontadas como processo a fim de poder orientar a aprendizagem da metodologia da pesquisa. Por ser complexa a pesquisa científica objetiva investigar para obter conhecimento específico e estruturado sobre um determinado tema. Constata-se a exigência da ampliação das linhas de pesquisa em todos os níveis e modalidades da educação desde o ensino fundamental, médio e superior. (PIRES, 2009).

\section{CONSIDERAÇÕES FINAIS}

Com os resultados encontrados durante a pesquisa é possível afirmar que o acadêmico tem muitas dificuldades na iniciação do curso, mas durante o período em andamento consegue ampliar o conhecimento no processo metodológico e interpretativo para desenvolver a produção cientifica, sustentada por regras e ações dando-os mais qualidade e entendimento na elaboração dos seus trabalhos.

A disciplina de M. C é um conhecimento que o acadêmico necessita ter para adquirir o hábito de estudar, ler e escrever, pois, o mesmo precisa aprender pesquisar e fazer seus próprios trabalhos com as regras básicas exigidas. As regras e passos metodológicos que são ensinados na universidade visam a inserção do estudante no mundo acadêmico-científico desenvolvendo nele hábitos pesquisa, investigação, leitura, interpretação e senso crítico que o acompanharão por toda sua existência. 
Este estudo permitiu evidenciar que a ciência é uma atividade metódica objetivando conhecer e interpretar a realidade fazendo que o indivíduo possa intervir baseandose em diretrizes, problemas formulados que são sustentados por regras e ações que se constituem em conhecimentos. Diante das novas exigências do mercado no mundo globalizado, se exige constantemente, profissionais, que tenham conhecimento, atitude, capacidade de pensar e se destacar. Teremos então que repensar uma melhor didática que tenha a finalidade de fazer o aprendiz pensar e fazer, aumentando sua eficiência, eficácia e qualidade no desenvolvimento das pesquisas compreendendo o contexto exigido.

\section{REFERENCIAS}

ANDRADE, Maria Margarida. Introdução à metodologia do trabalho científico: elaboração de trabalhos de graduação. 5. ed. São Paulo: Atlas, 2001.

ASSOCIAÇÃO BRASILEIRA DE NORMAS TÉCNICAS. NBR 14724: informação e documentação: trabalhos acadêmicos: apresentação. R.J: ABNT, 2005.

BABINI, J. El saber. Buenos Aires: Nueva Vison, 1957.

BAGNO, Marcos. A. Nada na língua é por acaso - por uma pedagogia da variação linguística. São Paulo: Parábola, 2007.

BORNHEIM, Gerd A. A metamorfose do olhar. In: NOVAES, Adauto (Org.). O olhar. São Paulo: Companhia das Letras, 1993.

BRASIL. Ministério da Educação. Coordenação de Aperfeiçoamento de Pessoal de Nível Superior (CAPES). Portal. Periódicos. CAPES: o portal brasileiro da informação. Disponível em: <http://www.periodicos.capes.gov.br/portugues/ index.jsp>. Acesso em 30-05-2019.

BRASIL. Ministério da Educação. LDB: Lei de Diretrizes e Bases da Educação Nacional: Lei n. 9.394, de 1996. Brasília: Senado Federal, Secretaria Especial de Editoração e Publicação, 1997. 
BRIDI, Jamile Cristina A., A pesquisa na formação do estudante universitário: a Iniciação Científica como espaço de possibilidades. 214 f. 2010. Tese (Doutorado) Programa de Pós-Graduação em Educação, Universidade de Campinas, Campinas, 2010.

BUNGE, Mario. Epistemologia. São Paulo: Edusp, 1980.

CAMPOS, L. M. L.; DINIZ, R. E. dá S. A prática como fonte de aprendizagem e o saber da experiência: o que dizem os professores de Ciências e Biologia. Investigações em Ensino de Ciências, Porto Alegre, v. 6, n. 1, 2004.

CERVO, A. L.; BERVIAN, P. A. Metodologia Científica. 5. ed. São Paulo: Pearson Pratice Hall, 2004.

CERVO, Amado Luiz; BERVIAN, Pedro Alcino. Metodologia científica: para uso dos estudantes universitários. 4. ed. São Paulo: MaKron Books, 2002.

CHAUÍ, Marilena. Introdução à história da filosofia. 2.ed. São Paulo: Companhia das letras, 2002

DEMO, Pedro. Metodologia cientifica em ciências sociais. 3. ed. rev. e atual. SP: Atlas, 1995.

, Pedro. Metodologia científica em ciências sociais. São Paulo: Atlas, 1981.

DESCARTES, R. Discurso do método, meditações, objeções e respostas, as paixões da Alma e Cartas. Introdução de Gilles-Gaston Granger; prefácio e notas de Gérard Lebrun. Trad. Guinsburg e Bento Prado Júnior. Editor Victor Civita. Abril Cultural. S. Paulo: 1956. (Col. Os Pensadores, vol. XV).

FERREIRA, Aurélio Buarque de Holanda. Aurélio Junior: Dicionário Escolar da Língua Portuguesa/Coordenação de Marina Baird Ferreira e Margarida dos Anjos; Ilustração Alex Sande - 2ª edição Curitiba PR; positivo, 2011. 
JAERGER, W. Paideia - a formação do homem grego. São Paulo: Martins Fontes, 2003.

KERLINGER, Fred N. Foundations of behavioral research. New York: Holt, Rinehart \&Winston, 1973.

KNECHTEL, Maria do Rosário. Metodologia da pesquisa em educação: uma abordagem teórico-prática dialogada. Curitiba: Intersaberes, 2014.

LAKATOS, Eva M. e Marconi, Marina A., "Metodologia Científica", Editora Atlas S.A., SP. 1991.

LEITE, F. H. C. Metodologia Científica. In: LEITE, F. H. C.; SAKAGUTI, S. T. Metodologia Científica/ Estatística II. Dourados-MS: UNIGRAN, 2009.

LIARD, Louis. Lógica. Tradução de Godofredo Rangel. 9 ed. São Paulo: Editora Nacional, 1979.

LIBÂNIO, João Batista. Introdução à vida intelectual. São Paulo: Loyola, 2001.

LUZURIAGA, Lorenzo. História da educação e da pedagogia. São Paulo: Companhia Editora Nacional, 2001.

MACIEL, Marcelo da Costa. "A contribuição do pensamento antigo e medieval para o desenvolvimento da Ciência Política", in FERREIRA, Lier Pires (Org.); GUANABARA, Ricardo; JORGE (Org.); Vladimyr Lombardo Jorge (Org.). Curso de Ciência Política: grandes autores do pensamento político e contemporâneo, R.J.: Elsevier, 2009.

MEC e Inep divulgam dados do Censo da Educação Superior 2016. http://portal.inep.gov.br/artigo/-/asset_publisher/B4AQV9zFY7Bv/content/mec-e-inepdivulgam-dados-do-censo-da-educacao-superior-2016/21206. Acessado: 14-072019.

MIALARET, Gaston. A formação dos professores. Coimbra: Livraria Almedina, 1991. 
PERINI, Mário. Para uma nova gramática do português brasileiro. 3ª . ed. São Paulo: Ática, 1996.

PINTO, Álvaro Vieira. Ciência e existência: problemas filosóficos da pesquisa científica. R.J.: Paz e Terra, 1979.

, M. J. F. A Metodologia da Pesquisa Científica como ferramenta na Comunicação Empresarial. Artigo, 2009. Disponível em: <http://www.comtexto.com.br/2convicomcomunicaMariaJoaquina.htm>. Acesso: 0504-2011.

PRODANOV, Cleber Cristiano. Metodologia do trabalho científico [recurso eletrônico]: métodos e técnicas da pesquisa e do trabalho acadêmico / Cleber Cristiano Prodanov, Ernani Cesar de Freitas. - 2. ed. - Novo Hamburgo: Feevale, 2013.

RAMOS, Fernanda Peres; NEVES, Marcos Cesar Danhoni; CORAZZA, Maria Júlia. A ciência moderna e as concepções contemporâneas em discursos de professorespesquisadores: entre rupturas e a continuidade. IN: Revista Electrónica de Enseñanza de las Ciencias Vol 10, № 1, 84-108 (2011). Disponível em: http://reec.uvigo.es/volumenes/volumen10/ART5_Vol10_N1.pdf Acesso em: 03 de dez. 2016.

REALE, G.; ANTISERI, D. História da filosofia: filosofia pagã antiga, v. 1 tradução: Ivo Storniolo. São Paulo: Paulus, 2003.

RODRIGUES. A. de. J. Metodologia Científica: completo e essencial para a vida universitária. São Paulo: Avercamp, 2006.

ROSA, Carlos Augusto de Proença. História da ciência: da antiguidade ao renascimento científico. 2. ed. Brasil: FUNAG, 2012.

SEABRA, Giovanni de Farias. A pesquisa cientifica: o método em questão. Brasília: Editora da UnB, 2001.

SEVERINO, A. J. Metodologia do trabalho científico. São Paulo: Cortez, 2002. 
, Antônio Joaquim. Educação, sujeito e história. São Paulo: Olho d'água, 2001.

, Antônio Joaquim. Metodologia do trabalho científico. 23. ed. rev. e atual. SP: Cortez, 2007.

SILVA. S. G. de. A contribuição da pesquisa no desenvolvimento da aprendizagem da criança nas séries iniciais. INAES, Instituto Natalense de Educação Superior, 2007.

TEIXEIRA C. A. D. A Formação Continuada de Professores e a Educação Inclusiva. 0 f. Dissertação (Mestrado em Educação) -Universidade Federal de Santa Maria. Orientador: Soraia Apoleão Reitas.2003.

, Elizabeth. As três metodologias: acadêmica, da ciência e da pesquisa. 7 . ed. Petrópolis, RJ: Vozes, 2010.

Miguel Henrique Benetti; WOLFF, Andrea Aníbia Ferreira; SOUZA, Débora Martins de. Contribuições de Sócrates para o método de aprendizagem à distância. IN Revista Científica UNAR (ISSN 1982-4920), Araras (SP), v.11, n.2, p.4352, 2015.

TRUJILLO FERRARI, Alfonso. Metodologia da ciência. 2 ed. R.J.: Kennedy, 1974.

UNIVERSIDADE NORTE DO PARANÁ. Sistema de Ensino Presencial Conectado. Projeto pedagógico do Curso Superior de Licenciatura em Pedagogia. Londrina: UNOPAR, 2006.

VALENTE, José Armando. Diferentes usos do Computador na Educação. Disponível em: Acesso em: 20 mar. 2011.

Silza M. P., VITALIANO, Célia R. Formação de professores reflexivos como condição necessária para a inclusão de alunos com necessidades educacionais especiais. In: Formação de professores para a inclusão de alunos com necessidades educacionais especiais. p. 43 -48. Londrina: EDUCEL, 2010. 
. Silza M. P, Pesquisa, comunicação e aprendizagem com o computador: o papel do computador no processo ensino-aprendizagem. In: ALMEIDA, M. E.; MORAN, J. M. (Orgs.) Integração das tecnologias na educação. Brasília: MEC/SEED, 2005.

VICENTINO, C.; DORIGO, G. História geral e do Brasil - 1 ed. - São Paulo: Scipione, 2001.

VINCENTAS, Lamanauskasa, Dalia Augieno. Development of Scientific Research Activity in University: A Position of the Experts Procedia - Social and Behavioral Sciences (167): 131 - 140, 2015.

\section{APÊNDICE - REFERÊNCIAS DE NOTA DE RODAPÉ}

3. M. C - Metodologia Científica.

4. EAD - Educação a Distância.

5. UNOPAR - Universidade Norte do Paraná, Polo de São Lourenço do Oeste - SC.

6. INEP- Instituto de Estudos e Pesquisas Educacionais Anísio Teixeira.

7. NBR- Normas Brasileiras.

Enviado: Julho, 2019.

Aprovado: Setembro, 2019. 